\title{
Effect of Sputtering Pressure on the Properties of Boron and Gallium Co-doped ZnO Thin Films
}

\author{
Mengfei $\mathrm{CHEN}^{\mathrm{a}}$, Jian $\mathrm{HUANG}^{\mathrm{b}} *$, Jin YANG ${ }^{\mathrm{c}}, \mathrm{Ke} \mathrm{TANG}^{\mathrm{d}}$, Yuanxi $\mathrm{LU}^{\mathrm{e}}$ and Linjun $\mathrm{WANG}^{\mathrm{f}}$ \\ School of Materials Science and Engineering, Shanghai University, No. 333 Nanchen Road, Shanghai \\ 200444, China

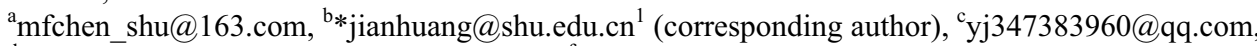 \\ dangke@ $@$ shu.edu.cn, ${ }^{\mathrm{e}} 536400351 @$ qq.com, ${ }^{\mathrm{f}}$ ljwang@shu.edu.cn
}

\begin{abstract}
B and Ga co-doped $\mathrm{ZnO}$ films were fabricated by RF magnetron sputtering method. The effects of sputtering pressure on the electrical, optical, structural and morphological properties of the films (BGZO) were investigated. As sputtering pressure increased up to $6 \mathrm{mTorr}$, the film crystallinity was improved. At the sputtering pressure of $6 \mathrm{mTorr}$, the films showed smooth and dense of film surface, lower resistivity and higher Hall mobility. It was also observed that all films showed high transparency in the visible range. The film showed blue shift of optical band gap with increaseing of sputtering pressure.
\end{abstract}

\section{Introduction}

For most optoelectronic devices such as flat panel displays, it is essential to use a transparent electrode consisting of a thin film of a transparent conducting oxide (TCO) semiconductor. Tin-doped indium oxide (commonly called ITO) thin films deposited by magnetron sputtering is the most common used TCO material for transparent electrode applications in the past decades[1,2]. Given the high cost and scarcity of indium, transparent conducting impurity-doped $\mathrm{ZnO}$, such as Al-, In-, B-and Ga-doped ZnO (AZO, IZO, BZO and $\mathrm{GZO}$, respectively), has recently attracted much attention as a promising alternative TCO material for application in flat-panel displays, window layers in thin film photovoltaic, and energy-efficient windows with low infra-red (IR) transmittance because of their excellent optical and electrical properties, low material costs, relatively low deposition temperature, non-toxicity, and stability in hydrogen plasma[3-7].

In order to develop TCO films with better properties and suitable for specialized applications previously proposed material development using multicomponent doping has recently been attracting much attention as a source of new TCO semiconductors, such as $\mathrm{B}$ and $\mathrm{Al}$ co-doped $\mathrm{ZnO}$ (BAZO), $\mathrm{Mg}$ and Ga co-doped $\mathrm{ZnO}$ (MGZO), $\mathrm{Al}$ and Ga co-doped $\mathrm{ZnO}$ (AGZO) [8-10]. Among those co-doped $\mathrm{ZnO}$ films, relatively few results have been reported on $\mathrm{B}$ and $\mathrm{Ga}$ co-doped $\mathrm{ZnO}$ films. Ga-doped $\mathrm{ZnO}$ film has several merits such as more resistant to oxidation, closer ionic radius of $\mathrm{Zn}^{2+}$ compared to $\mathrm{Al}$-doped $\mathrm{ZnO}$ films,

* Corresponding author: jianhuang@shu.edu.cn 
indicating that it allows minimizing the $\mathrm{ZnO}$ lattice deformations even at high $\mathrm{Ga}$ doping concentrations compared to the other impurities [11]. B-doped $\mathrm{ZnO}$ film exhibits high transparency and improved thermal stability $[12,13]$. B and Ga co-doped $\mathrm{ZnO}$ films are expected to show some improvements in electrical and optical properties of TCOs.

In this work, $\mathrm{B}$ and $\mathrm{Ga}$ co-doped $\mathrm{ZnO}$ (BGZO) films were prepared by RF magnetron sputtering. The effect of sputtering pressure on optical, electrical and structural properties of BGZO films was studied in detail.

\section{Experiment}

$\mathrm{B}$ and $\mathrm{Ga}$ co-doped $\mathrm{ZnO}$ (BGZO) films were deposited on glass substrate by $\mathrm{RF}$ magnetron sputtering. A ceramic target was employed: $\mathrm{ZnO}$ target with $1.8 \mathrm{wt} \% \mathrm{Ga}_{2} \mathrm{O}_{3}$ and $0.2 \mathrm{wt} \% \mathrm{~B}_{2} \mathrm{O}_{3}$ (purity $99.99 \%$ ), the diameter of which was $101.6 \mathrm{~mm}$. Before the deposition of BGZO films, glass substrates were cleaned with ethyl alcohol. The vacuum chamber was evacuated until the residual gas pressure was less than $5 \times 10^{-7}$ Torr. The thicknesses of all the prepared BGZO films were about $200 \mathrm{~nm}$ controlled by a vibrating quartz crystal. Sputtering was performed at room temperature under an Ar atmosphere with an operating RF power of $150 \mathrm{~W}$. The sputtering pressure was varied from $3 \mathrm{mTorr}$ to $7.5 \mathrm{mT}$ Torr. The influence of sputtering pressure on properties of BGZO films was investigated.

The structural properties of the films were investigated by X-ray diffraction (XRD $3 \mathrm{KW}$ D/MAX-2200V PC, CuK $\alpha 1, \lambda=0.154056 \mathrm{~nm})$. The optical transmission of the films was measured using a UV-visible spectrophotometer (ShimadzuUV-2501 PC) and the optical bandgap (Eg) was evaluated from the $(\alpha \mathrm{hv})^{2}$ vs. hv (photon energy) plot. The electrical properties of the films were analyzed by Hall effect measurement system (Accent model HL5500PC). In addition, the surface morphology was analyzed by Scanning electron microscopy (SEM, Hitachi S-4800).

\section{Results and Discussions}

To investigate the sputtering pressure on the microstructure of BGZO films, XRD analysis was performed as shown in Figure 1. It is obviously that all the samples had a strong (002) peak at $2 \theta$ near $34.4^{\circ}$ in the angle region from $20^{\circ}$ to $70^{\circ}$, which indicate that the BGZO films had a well-developed wurtzite structure and a good c-axis orientation perpendicular to the substrate. It is also found in Figure 1 that the intensity of (002) peak of the BGZO films increase with the increasing of sputtering pressure up to $6 \mathrm{mTorr}$ and then decrease with further increasing of sputtering pressure, which indicates an improvement of the crystalline quality prepared at proper sputtering pressure. 


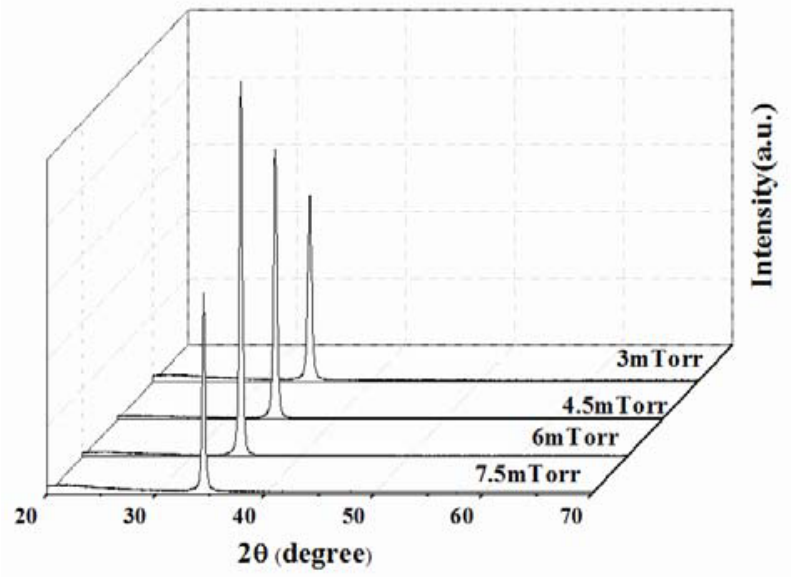

Figure 1. The XRD patterns of BGZO films under different sputtering pressure

The sputtering pressure dependences of surface morphology for BGZO films are also revealed by the SEM, as shown in Figure 2. We can observe that when the sputtering pressure is 6mTorr, the BGZO films shows the uniform crystalline size and better smooth and dense of film surface. As the sputtering pressure increase form $3 \mathrm{mT}$ Torr to $7.5 \mathrm{mT}$ Torr, the grain size slightly decrease, especially when the sputtering pressure is $7.5 \mathrm{mTorr}$.

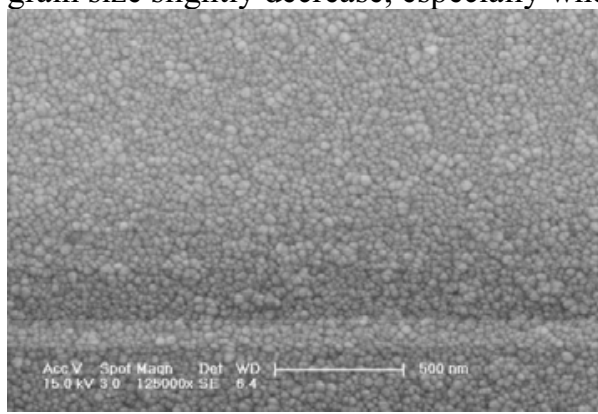

(a)

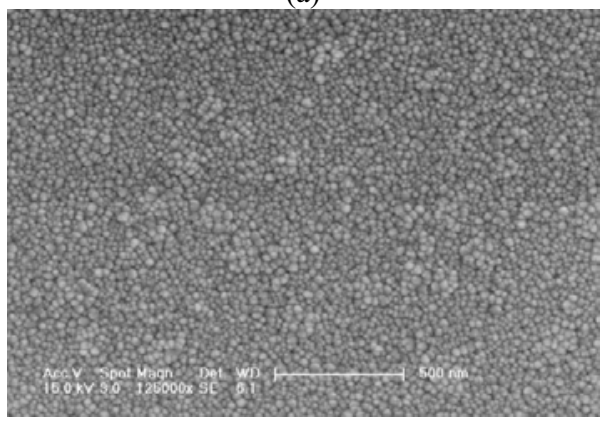

(c)

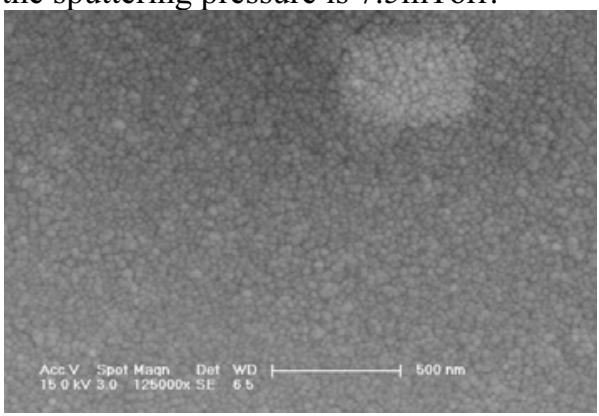

(b)

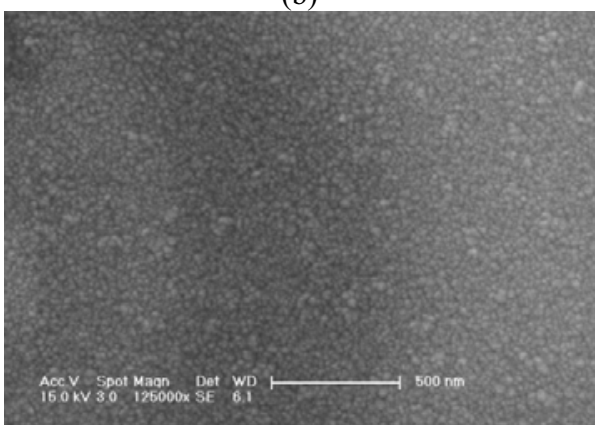

(d)

Figure 2. SEM images of BGZO films under different sputtering pressure:(a) 3mTorr, (b) 4.5mTorr, (c) $6 \mathrm{mT}$ orr and (d) $7.5 \mathrm{mTorr}$

Figure 3 shows the carrier mobility, concentration and resistivity of the BGZO films as a function of sputtering pressure. From the figure, we could find that the carrier concentration of the grown films gradually increased from $3.8 \times 10^{20} \mathrm{~cm}^{-3}$ to $6.1 \times 10^{20} \mathrm{~cm}^{-3}$ as the sputtering pressure increased from $3 \mathrm{mT}$ Torr to $7.5 \mathrm{mT}$ Torr. The carrier mobility of the BGZO films increased with increasing the sputtering pressure up to $6 \mathrm{mT}$ Torr and then decrease with further 
increasing of sputtering pressure. The increased mobility is attributed to the improved crystallinity that weakens inter-crystallite boundary scattering and increases carrier lifetime [14].

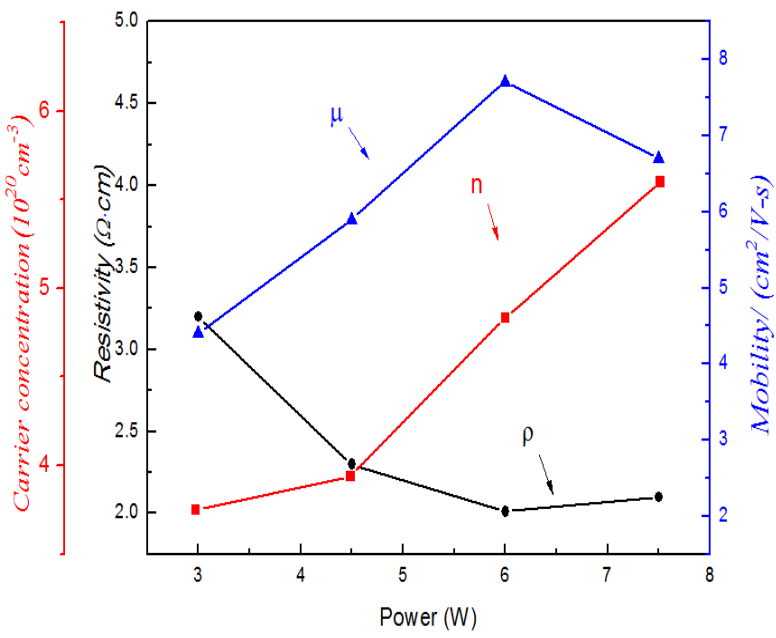

Figure 3. The resistivity ( $\rho$ ), carrier concentration (n), and Hall mobility $(\mu)$ of BGZO films under different sputtering pressure.

It is also found in Figure 3 that the resistivity of the BGZO films decrease gradually with increasing of sputtering pressure up to $6 \mathrm{mT}$ Torr. As reported, the resistivity of the films is dominated by the carrier concentration and mobility as the following equation [15]: $\rho=1 / \mathrm{Ne} \mu$, where, $\rho$ is resistivity, $\mathrm{N}$ is carrier concentration and $\mu$ is mobility. From the equation, the increased carrier concentration and mobility of BGZO films is the reason for decreased film resistivity with sputtering pressure in the 3-6 mTorr range.

The optical transmittance spectra of BGZO films with different sputtering pressure are shown in Figure 4, from which we could find that all the BGZO films showed high optical transmittance $(>85 \%)$ including substrates in the visible range, which is important for applications. The high transparency is associated with the good structural homogeneity and crystallinity of the films. With the increase of sputtering pressure, the absorption edge of the BGZO films shifts to the shorter wavelength, which is due to the Burstein-Moss effect [16].

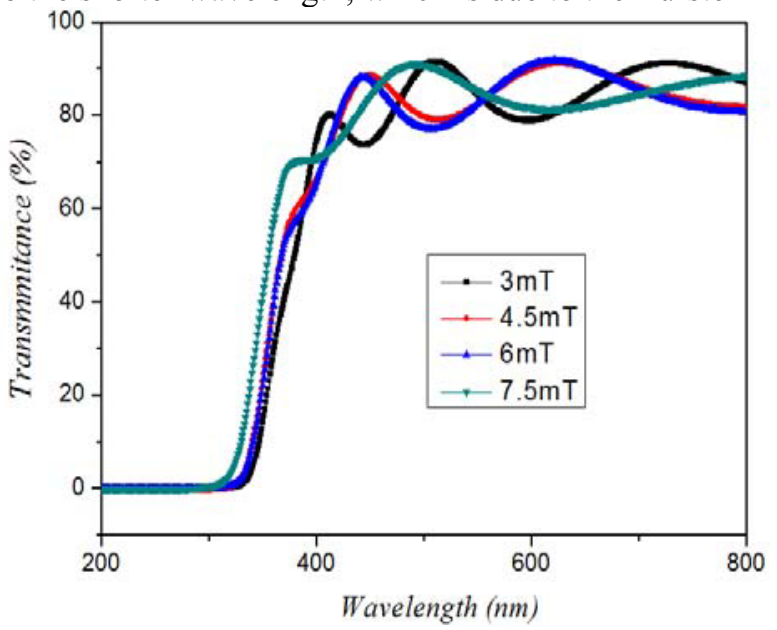

Figure 4. The transmission spectra of BGZO films deposited under different sputtering pressure. 


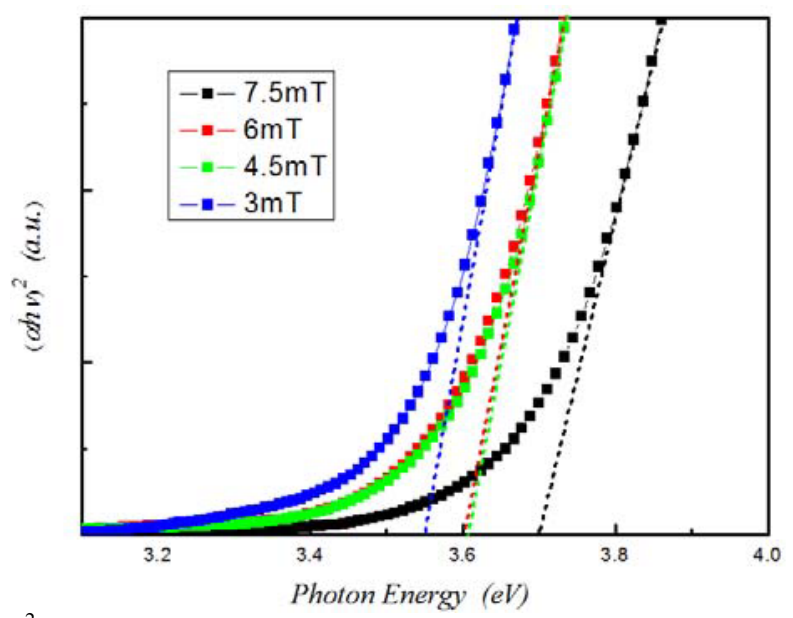

Figure 5 The $(\alpha h v)^{2}$ vs. hv plots for BGZO films deposited under different sputtering pressure.

The fundamental absorption corresponds to the electron excitation from valance band to conduction band and can be used to evaluate the value of the optical band gap. Figure 5 shows the plot of $(\alpha h v)^{2}$ versus hv, where $\alpha$ is the optical absorption coefficient and hv is the energy of the incident photon. The optical band gap of the films is determined by applying the Tauc model, and the Davis and Mott model [17] in the high absorbance region: $\alpha h v$ $=\mathrm{C}\left(h v-\mathrm{E}_{\mathrm{g}}\right)^{\mathrm{n}}$, where $\mathrm{C}$ is a constant, $h v$ is the photon energy and $\mathrm{E}_{\mathrm{g}}$ is the optical band gap. For a direct transition, $n=1 / 2$. As $\mathrm{ZnO}$-based films have a direct band gap, the band gap of the films could be calculated by plotting $(\alpha h v)^{2}$ versus $h v$ (as shown in Figure 5). The extrapolation of the curve to the energy axis give bandgap of about $3.55 \mathrm{eV}, 3.6 \mathrm{eV}, 3.61 \mathrm{eV}$ and $3.7 \mathrm{eV}$ for BGZO films prepared at $3 \mathrm{mT}$ Torr, $4 \mathrm{mT}$ Torr, $6 \mathrm{mT}$ Torr and $7.5 \mathrm{mT}$ Torr, respectively. The blue shift of optical band gap with increaseing of sputtering pressure is relates to the increase in the carrier concentration blocking the lowest states in the conduction band, well known as the Burstein-Moss effect [16].

\section{Summary}

$\mathrm{B}$ and $\mathrm{Ga}$ co-doped $\mathrm{ZnO}$ films were deposited by radio frequency magnetron sputtering with various sputtering pressure. The structural, electrical and optical properties of the BGZO films are dependent on the sputtering pressure. The crystal structure of all the BGZO films is hexagonal wurtzite and shows highly c -axis orientation. As sputtering pressure increases up to $6 \mathrm{mT}$ Torr, the crystallinity is improved. The carrier mobility of the BGZO films increased with increasing the sputtering pressure up to $6 \mathrm{mTorr}$. The carrier concentration increase and resistivity decrease with increasing the sputtering pressure. All the BGZO films show high optical transmittance in the visible range and blue shift of optical band gap with increaseing of sputtering pressure.

\section{Acknowledgment}

This work was funded by the National Natural Science Foundation of China under Grant No. 61176072, the Doctoral Fund of Ministry of Education of China under Grant No. 
20123108120021. The authors also thank Instrumental Analysis and Research Center of Shanghai University for the XRD work carried out.

\section{References}

1. T. Minami: Semicond. Sci. Technol.Vol. 20 (2005), p. S35

2. A. L. Dawar and J. C. Joshi: J. Mater. Sci. Vol. 19 (1984), p. 1

3. R. Martins, P. Barquinha, I. Ferreira, L. Pereira, G. Goncalves, E. Fortunato: J. Appl. Phys. Vol. 101 (2007), p.044505

4. T. Yamada, A. Miyake, S. Kishimoto, H. Makino, N. Naoki, T. Yamamoto: Appl. Phys. Lett. Vol. 91 (2007), p. 051915

5. T. Minami, H. Nanto, H. Sato: Thin Solid Films Vol.164 (1988), p.275

6. Y. Yamamoto, K. Saito, K. Takahashi, M. Konagai: Sol. Energy Mater. Sol. Cells Vol.65 (2001), p 125

7. M. Lorenz, E.M. Kaidashev, H.V. Wenchstern, V. Riede, C. Bundesmann, D. Spemann: Solid-State Electron. Vol. 47 (2003), p 2205

8. D.W. Kang, J.Y. Kwon, D.J. Lee, M.K. Han: J. Electrochem. Soc. Vol. 159 (2012), p H61

9. S.W. Shin, G.L. Agawane, I.Y. Kim, S.H. Jo, M.S. Kim, G.S. Heo, J.H. Kim, J.Y. Lee: Surf. Coat. Technol. Vol.231 (2013) p 364

10. W. Lee, S. Shin, D.R. Jung, J. Kim, C. Nahm, T. Moon, B. Park: Curr. Appl. Phys. Vol. $12(2012)$ p 628

11. Q.B. Ma, Z.Z. Ye, H.P. He, S.H. Hu, J.R. Wang, L.P. Zhu, Y.Z. Zhang, B.H. Zhao: J. Cryst. Growth Vol. 304 (2007), p 64

12. C.Y. Tsay, W.T. Hsu: Ceramics International Vol.39 (2013), p 7425

13. H. Zhu, H. Jia, D. Liu, Y. Feng, L. Zhang, B. Lai, T. He, Y. Ma: Appl. Surf. Sci. Vol.258 (2012), p 6018

14. H. Kim, J.S. Horwits, G. Kushto, A. Pique, Z.H. Kafafi, C.M. Gilmore: Journal of Applied Physics Vol.88 (2000), p 6021

15. Y. Igasaki, H. Saito: Thin Solid Films Vol.199 (1991), p 223

16. E. Burstein: Physical Review Vol.93 (1954), p 632

17. N. Serpone, D. Lawless, R. Khairutdinov: Journal of Physics Chemistry Vol.99 (1995), p 16646 